\title{
Dopamine Transmission in the Human Striatum during Monetary Reward Tasks
}

\author{
David H. Zald, ${ }^{1}$ Isabelle Boileau, ${ }^{2,3}$ Wael El-Dearedy, ${ }^{4}$ Roger Gunn, ${ }^{5}$ Francis McGlone, ${ }^{6}$ Gabriel S. Dichter, ${ }^{1}$ and \\ Alain Dagher ${ }^{2,3}$ \\ ${ }^{1}$ Department of Psychology, Vanderbilt University, Nashville, Tennessee 37212, ${ }^{2}$ McConnell Brain Imaging Centre, Montreal Neurological Institute, \\ Montreal, Quebec, Canada H3A 2T5, ${ }^{3}$ Department of Neuroscience, McGill University, Montreal, Quebec, Canada H3A 2T5, ${ }^{4}$ School of Computing and \\ Mathematical Sciences, Liverpool John Moores University, Liverpool LI 2TZ, United Kingdom, ${ }^{5}$ GlaxoSmithKline, Greenford, United Kingdom UB6 OHE, \\ and ${ }^{6}$ Unilever Research, Port Sunlight, Wirral, United Kingdom CH63 3JW
}

Previous studies have demonstrated the ability of the $\left[{ }^{11} \mathrm{C}\right]$ raclopride positron emission tomography (PET) technique to measure behaviorally induced changes in endogenous dopamine transmission in humans. However, these studies have lacked well matched sensorimotor control conditions, making it difficult to know what sensory, cognitive, or motor features contributed to changes in dopaminergic activity. Here we report on $\left[{ }^{11} \mathrm{C}\right]$ raclopride PET studies in which healthy humans performed card selection tasks for monetary rewards. During separate scans, subjects completed a variable ratio (VR) reward schedule with a $25 \%$ reward rate in which they did not know the outcome of their responses in advance, a fixed ratio (FR) $25 \%$ reward schedule in which outcomes were fully predictable, and a sensorimotor control (SC) condition involving similar sensory and motor demands but no rewards. Relative to the SC condition, the FR schedule produced only modest increases in dopamine transmission and no decreases relative to the SC condition. In contrast, the VR schedule produced significant increases in dopamine transmission in the left medial caudate nucleus while simultaneously producing significant decreases in other areas of the caudate and putamen. These data indicate: (1) the feasibility of measuring alterations in dopamine transmission even after controlling for sensorimotor features and (2) the complex and regionally specific influence of VR schedules on dopamine transmission. The implications of these results are discussed in relation to conflicting models of dopaminergic functioning arising from studies using electrophysiological and microdialysis techniques in animals.

Key words: behavior; caudate; dopamine; motivation; PET; positron emission tomography; reward; nucleus accumbens

\section{Introduction}

Although dopamine (DA) is widely implicated in aspects of reward processing, little information is available regarding the conditions that provoke DA transmission in humans. Considerable evidence indicates that the binding potential (BP) of the radiolabeled $\mathrm{D}_{2}$ ligand $\left[{ }^{11} \mathrm{C}\right.$ ]raclopride is inversely related to the synaptic concentration of DA at the time of scanning. Increases in DA transmission lead to reductions in $\left[{ }^{11} \mathrm{C}\right]$ raclopride $\mathrm{BP}$ in the striatum (Dewey et al., 1993; Breier et al., 1997; Endres et al., 1997; Hartvig et al., 1997; Laruelle, 2000), whereas decreases in DA transmission produce increases in $\left[{ }^{11} \mathrm{C}\right]$ raclopride BP (Dewey et al., 1992; Ginovart et al., 1997). Because of this relationship, changes in $\left[{ }^{11} \mathrm{C}\right]$ raclopride $\mathrm{BP}$ can be used to detect modulation of DA transmission during different conditions. In humans, this approach has mostly been used to study the effects of therapeutic

Received 0ct. 14, 2003; revised Feb. 23, 2004; accepted Feb. $28,2004$.

This work was supported by a research grant from Unilever Research and National Science Foundation Grant 0332219. We thank S. Sechet, A. Reilhac, and A. Evans for assistance in developing and applying the motion detection and realignment procedures, the staff of the McConnell Brain Imaging Center PET unit, and anonymous reviewers for helpful comments.

Correspondence should be addressed to David H. Zald, Department of Psychology, Vanderbilt University, 325 Wilson Hall, 11121 st Avenue South, Nashville, TN 37212. E-mail: david.zald@vanderbilt.edu.

DOI:10.1523/JNEUROSCI.4643-03.2004

Copyright $\odot 2004$ Society for Neuroscience $\quad 0270-6474 / 04 / 244105-08 \$ 15.00 / 0$ agents and drugs of abuse that act on the DA system (Drevets et al., 2001; Volkow et al., 2001; Leyton et al., 2002). In a novel study, Koepp et al. (1998) demonstrated that the technique can also be used to assess changes in DA transmission during behavioral tasks relative to a resting baseline. However, the use of a resting control condition raises interpretational issues because of the number of sensory, motor, and cognitive features that differed across conditions. Cognitive neuroimaging has prospered through the development of paradigms in which all but one or two variables are held constant across conditions. This provides greater interpretational specificity than can be obtained with contrasts to resting conditions. Here we demonstrate the feasibility of fusing this cognitive neuroimaging approach with the $\left[{ }^{11} \mathrm{C}\right]$ raclopride technique.

We specifically measured the extent to which differences in monetary reinforcement schedules influence DA transmission. Electrophysiological studies in monkeys increasingly emphasize the importance of unpredictability and uncertainty in phasic DA cell firing. For instance, these studies indicate that DA neurons fire for brief periods $(<300 \mathrm{msec})$ in response to unpredictable rewards, suppress their firing when expected rewards are withheld, and show little modulation in response to well predicted rewards (Mirenowicz and Schultz, 1994). However, a wealth of data from animal studies using drug manipulations, in vivo mi- 


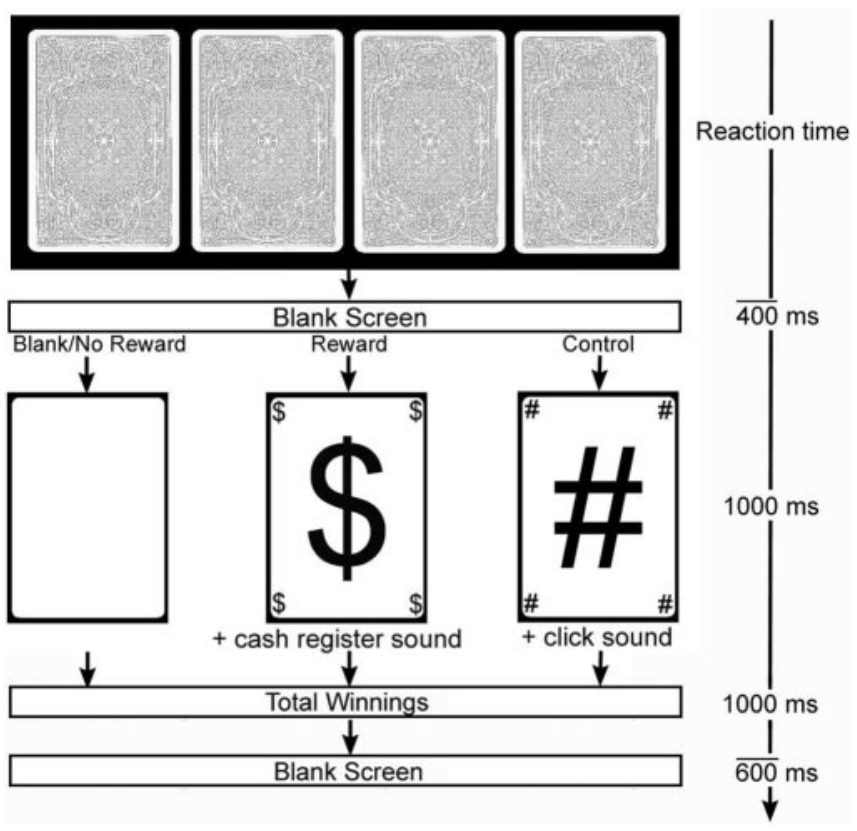

Figure 1. Schematic representation of the stimulation task. In the VR condition, subjects received either blank (no reward) cards or reward cards at a ratio of 3:1 using a pseudorandom schedule. In the FR condition, subjects received three consecutive blank (no reward) cards followed by a reward card on every fourth card selection. In the SC condition, subjects received three blank cards followed by a control card (\# sign) on every fourth selection. The length of the blank screens appearing after each card selection and at the end of each trial was variable and based on exponential random distributions centered around 400 and $600 \mathrm{msec}$, respectively.

crodialysis, and lesions of DA fibers indicate the importance of DA in incentive motivational tasks that require the animal to make responses, even when reward contingencies are predictable (McCullough et al., 1993; Cousins et al., 1994; Wilson et al., 1995; Salamone et al., 1997, 1999; Ikemoto and Panksepp, 1999). These two lines of data are not mutually exclusive, in that they may reflect different aspects of DA functioning, such as phasic versus more enduring statewise DA activity. Nevertheless, they lead to different predictions about the extent to which DA may be modulated by differences in reinforcement contingencies. To address this issue, we exposed subjects to variable ratio (VR) and fixed ratio (FR) monetary reward schedules that involved a similar frequency and amount of reward but differed in the level of predictability on each trial.

\section{Materials and Methods}

Subjects. Ten healthy subjects (four right-handed males, five righthanded females, and one left-handed female; 23-38 years of age; mean age, 27) participated in the study. All subjects gave written informed consent approved by the Montreal Neurological Institute Research Ethics Committee. One male was excluded as a result of movement during scans, leaving a total of nine subjects in all analyses. All subjects were instructed to not eat a meal or drink coffee within $2 \mathrm{hr}$ of the study (three subjects reported having small snacks $\sim 1 \mathrm{hr}$ before scanning). Subjects were also instructed not to smoke cigarettes before the study (two subjects were occasional smokers and reported abiding by this demand).

Stimulation paradigm. Figure 1 displays a schematic of the three tasks. On each trial, subjects selected one of four cards displayed on a computer screen positioned $\sim 1 \mathrm{~m}$ from the subject's eyes. Subjects responded with their preferred hand using either a four-button press device or computer keyboard. On rewarded trials, a card with a $\$$ sign appeared for $1 \mathrm{sec}$ and the subjects heard the sound of a cash register door opening. Each $\$$ sign was worth $\$ 1$ Canadian, and subjects saw a running total of their earnings after each trial. In the VR reward condition, subjects did not know which trials would lead to the receipt of a reward or which card would signal the reward, except that the same card could not provide a reward in two consecutive trials. Rewards were given in a pseudorandom temporal pattern with an average of one reward in every four trials. In contrast, in the FR reward condition, subjects were informed that on every fourth pick they would receive $\$ 1$, regardless of which card they picked. The critical difference between the FR and VR tasks involves the level of uncertainty associated with each trial. In the VR condition, there is uncertainty regarding whether or not a reward will occur, and the expectation of a possible reward is met or not met on every trial. In contrast, during the FR condition, the subject's expectation of reward or nonreward is met on every trial (i.e., the subject can fully predict that they will not receive a reward on three consecutive trials, and they similarly can fully predict the outcome of the subsequent rewarded trial). Additionally, subjects completed a sensorimotor control (SC) condition, in which they selected cards but received no reward. During the SC condition, a meaningless symbol was displayed on every fourth card, accompanied by a click sound. Subjects were informed in advance that this would occur every fourth card. In both the FR and SC conditions, subjects were told that they could not pick the same card twice in a row and were requested to vary their card selection across all four cards to prevent selecting a more limited range of cards than during the VR condition. Examination of the responses indicated that all subjects adhered to this instruction. The three conditions were counterbalanced across the nine subjects who provided valid data. The tasks were started, on average, 17 min before tracer injection and continued until the subject had completed 480 trials or $30 \mathrm{~min}$ of playing, whichever came first. Subjects received a 2 min break to rate their mood on the Positive Affect Negative Affect Schedule (PANAS) (Watson et al., 1988) after 10 min of task performance, with a second break and PANAS rating occurring after an additional 10 min of the task and a final rating on completion of the task.

Positron emission tomography imaging and analysis. Subjects completed positron emission tomography (PET) scans on 3 separate days, with each scan starting at approximately the same time to control for diurnal variations in DA functioning. Scanning was accomplished with a Siemens/CTI ECAT Exact HR + camera (CTI PET Systems, Inc., Knoxville, TN) in three-dimensional (3-D) mode with a resolution of $4.8 \times$ $4.8 \times 5.6 \mathrm{~mm}$ full width at half maximum (FWHM) at the center of the field of view (Spinks et al., 2000). Subjects received a transmission scan for attenuation correction using rotating rods of ${ }^{68} \mathrm{G} /{ }^{68} \mathrm{Ga}$ before the collection of emission scans. At the start of each PET scan, subjects received a slow bolus intravenous injection of $7 \mathrm{mCi}\left[{ }^{11} \mathrm{C}\right]$ raclopride over $120 \mathrm{sec}$. Twenty-six emission scan frames of increasing length were then collected.

All emission scans were reconstructed using a $6 \mathrm{~mm}$ FWHM Hanning filter, producing an estimated final FWHM of $10-12 \mathrm{~mm}$. For purposes of anatomical localization and spatial normalization, all subjects additionally underwent T1-weighted magnetic resonance imaging (MRI) using a Siemens 1.5T Vision scanner. PET emission frames were summed, registered to their corresponding MRI (Woods et al., 1993), and transformed into standardized stereotaxic space (Talairach and Tournoux, 1988) by means of an automated feature-matching algorithm (Collins et al., 1994). All transformed images were visually inspected to ensure that there were no alignment errors.

Because of the large differences in $\left[{ }^{11} \mathrm{C}\right]$ raclopride BP between the striatum and adjacent extrastriatal regions, head movement during a scan session has the potential to produce substantial errors in voxelbased analyses of $\left[{ }^{11} \mathrm{C}\right]$ raclopride BP. Traditional approaches to detect motion within a scan session, which were developed for regional cerebral blood (rCBF) flow data sets, are not appropriate for bolus $\left[{ }^{11} \mathrm{C}\right]$ raclopride studies, because the spatial distribution of radioactivity changes with time, initially reflecting tracer delivery (i.e., rCBF) and later reflecting D2 receptor distribution (Dagher et al., 1998). To detect and correct potential movement-related errors, we used a novel automated movement-detection procedure designed by S. Sechet, A. Reilhac, R. N. Gunn, A. Evans, and A. Dagher (unpublished observations). The method uses the subject's MRI, which is segmented automatically into several user-determined regions, using the program ANIMAL (Automatic Nonlinear Image Matching and Anatomical Labeling) (Collins et al., 1995). 
Table 1. Peak coordinates of areas showing significant changes in DA release

\begin{tabular}{|c|c|c|c|c|c|c|}
\hline Location & Talairach coordinates & \% BP change mean (SD) & $t$ value & Corrected $p$ value & Cluster size $\left(\mathrm{mm}^{3}\right)$ & Corrected $p$ value \\
\hline \multicolumn{7}{|l|}{ VR-SC } \\
\hline Left medial caudate & $-6,8,4$ & $-6.3(16.0)$ & 5.1 & $<0.0005$ & 800 & $<0.05$ \\
\hline Left lateral putamen & $-30,-2,0$ & $9.1(20.3)$ & -4.4 & $<0.01$ & 1288 & $<0.01$ \\
\hline \multicolumn{7}{|l|}{$F R-V R$} \\
\hline Right central caudate & $12,16,12$ & $-8.3(12.7)$ & 4.9 & $<0.005$ & 720 & $<0.05$ \\
\hline Left lateral putamen & $-26,6,6$ & $-8.7(11.1)$ & 4.7 & $<0.005$ & $2656^{a}$ & $<0.0005$ \\
\hline Left lateral caudate/medial putamen & $-18,16,6$ & $-8.2(5.9)$ & 4.3 & $<0.05$ & $2656^{a}$ & $<0.0005$ \\
\hline
\end{tabular}

Areas showing decreases in $\left[{ }^{11} \mathrm{C}\right]$ raclopride $\mathrm{BP}$ (indicating increased DA transmission) in the stimulation relative to the comparison condition are reported as positive tvalues. Areas showing increased $\left[{ }^{11} \mathrm{C}\right]$ raclopride $\mathrm{BP}$ (indicating decreased DA transmission) in the stimulation relative to the comparison condition are reported as negative $t$ values and appear in bold. Percentage change corresponds to spherical regions of interest, with a $2 \mathrm{~mm}$ radius around the peak coordinate. $p$ values for the statistical significance of cluster size are reported based on a traditional static contrast of BP estimates using $8 \mathrm{df}$. All peaks reported were also highly statistically significant when the analysis of extent used statistical parametric maps based on the residuals $t$ test.

${ }^{a}$ The left lateral putamen and lateral caudate/medial putamen peak in the FR-UR contrast reflect two distinct maxima within a contiguous cluster.

Each region is then assigned a generic $\left[{ }^{11} \mathrm{C}\right]$ raclopride time-activity curve based on data collected from normal volunteers using our ECAT $\mathrm{HR}+$ camera. Thus, we generate a four-dimensional data set, which is then filtered using the characteristics of the ECAT HR + . This PET template, which is generated for each subject, has the appropriate spatial and temporal characteristics to serve as a target for realignment. We then use this realignment algorithm to determine the amount of movement in every frame relative to this target volume. When the algorithm detects significant movement, the realignment data are used to realign the subject's data. Previous Monte Carlo simulations using a simulated phantom based on ECAT HR $+3-\mathrm{D}\left[{ }^{11} \mathrm{C}\right]$ raclopride data indicate that for alignment mismatches of $4-12 \mathrm{~mm}$ in the $x, y$, and $z$ axes, the average residual error after alignment correction using this technique is $\sim 0.25 \pm$ $0.2 \mathrm{~mm}$. Residual errors after correction of rotational displacements of $2-6^{\circ}$ is $0.1 \pm 0.1^{\circ}$. Thus, the method appears to recover the vast majority of translational or rotational errors caused by movement across temporal frames.

Based on this procedure, only two subjects showed evidence of significant movement during scans. One subject showed movement on all three scans, and in one scan this movement was too large to correct (because of potential distortions induced by the mismatch between the displaced emission scans and the attenuation scan). This subject was therefore removed from group analysis. A second subject showed evidence of movement during one condition. This subject's scans were realigned to remove the motion using the procedure described above. Post hoc analysis, with and without motion correction for this subject, produced only minimal effects on the group results. No other subjects showed evidence of movement exceeding half of the image FWHM, a threshold below which such movement should have minimal effects.

Voxel-wise BP of $\left[{ }^{11} \mathrm{C}\right]$ raclopride was calculated using a simplified reference tissue method (Lammertsma and Hume, 1996; Gunn et al., 1997). Voxel-wise statistical analysis followed techniques described by Aston et al. (2000) that allow for the incorporation of the dynamic information (separate time frames) in parameter estimates, and thus provides high accuracy in the estimate of compartmental model parameters, as well as substantially more degrees of freedom than can be achieved when considering only final BP values for statistical testing. The technique is based on the nonlinear least squares theory and uses residuals to calculate the variance in parameter estimates. This method was demonstrated previously to be insensitive to changes in cerebral blood flow at the levels likely to occur in a behavioral task (Aston et al., 2000). Because this procedure uses each time frame of data and is based on the residuals at each time point (which are independent), the method provides greater degrees of freedom than are possible with analyses using a single static contrast of two images. The approach has been found to produce minimal false-positive activations in both simulated and actual test-retest data (Aston et al., 2000). In addition to the magnitude of change across conditions, we also analyzed the extent of activated regions. Because the methods of Aston et al. (2000) have not been validated in terms of extent data, we based extent analysis on a simple voxel-wise contrast between static BP estimates across conditions producing a $t$ test with $8 \mathrm{df}$. The statistical significance of both magnitude and extent was assessed using the methods of Worsley et al. (1996), in which significance levels are corrected for the number of resolution elements within the search volume. We set the search volume equal to the area with $\left[{ }^{11} \mathrm{C}\right]$ raclopride $\mathrm{BP}$ $>1.0$ across subjects (this is essentially equivalent to the volume of the basal ganglia, because this is the only region with specific binding of $\left[{ }^{11} \mathrm{C}\right]$ raclopride). A FWHM of $10 \mathrm{~mm}$ was used in the calculation of the number of resolution elements. Because this estimate represents the lower bound of the effective image resolution, the resulting number of resolution elements may be overestimated, and consequently the significance levels are potentially biased in a conservative direction. These calculations led to a corrected significance threshold $(p<0.05)$ of approximately $t=3.85$. Peaks exceeding an uncorrected $p$ value of $<0.005$ are also reported in Results to capture more moderate trends in the data, but such peaks must be treated with caution because they did not reach more rigorous levels of statistical significance.

\section{Results}

\section{Behavioral data}

Nine subjects provided valid PET data, and all statistics derive from those subjects. There was a significant effect of condition on reaction time (repeated measures; $F_{(1,8)}=20.4 ; p<0.005$ ), with the fastest reaction times arising during the VR condition (mean, $385.1 \mathrm{msec}$; SD, 67.4), followed by the FR (mean, 473.9 msec; SD, 62.9) and the SC condition (mean, $508.2 \mathrm{msec}$ SD, 96.4). All subjects completed the full 480 trials for the VR condition within the time limit. Six of the nine subjects also completed the 480 trials for the FR and SC conditions, but the remaining three subjects reached the time limit before finishing all trials (FR mean trials, 473; SC mean trials, 469). Total winnings were similar across the two reward conditions (FR, \$118; VR, \$120).

\section{Mood data}

Analysis of positive affect ratings revealed a significant main effect of condition, (repeated measures; $F_{(2,7)}=6.35 ; p<0.03$ ), with the VR condition producing the most positive affect (mean, 132.3; SD, 24.9), followed by the FR condition (mean, 118.0; SD, 29.3); the SC condition produced the least positive effect (mean, 91.9; SD, 38.6). Negative affect levels were not significantly influenced by condition $(p>0.95)$.

\section{DA transmission}

DA transmission was indexed by changes in $\left[{ }^{11} \mathrm{C}\right]$ raclopride $\mathrm{BP}$ across conditions. Because of the inverse relationship between $\left[{ }^{11} \mathrm{C}\right]$ raclopride BP and DA transmission, decreases in BP indicate an increase in DA transmission. Table 1 displays the coordinates, percentage change, and $t$ value of changes in $\left[{ }^{11} \mathrm{C}\right]$ raclopride BP.

The VR condition induced a significant decrease in BP of $\left[{ }^{11} \mathrm{C}\right]$ raclopride relative to the SC condition. Figure 2 displays a $t$ statistic map of this change in BP. The maximal area of BP de- 
crease localized to the medial left caudate nucleus (intermediate in the dorsoventral axis). The area demonstrating reduced $\mathrm{BP}$ only comprised a small portion of the striatum, suggesting topographical specificity in DA transmission. Moreover, other portions of the left striatum showed increases in $\mathrm{BP}$, indicating a reduction in DA transmission (Dewey et al., 1992; Ginovart et al., 1997). Specifically, the left lateral putamen demonstrated greater $\mathrm{BP}$ in the VR condition than the SC condition (Fig. 3). There was also a trend toward greater BP in the VR condition than the SC condition within the anteriolateral head of the caudate nucleus $(x=-16 ; y=22 ; z=0$; $t=-3.7)$; this failed to reach statistical significance after correction for multiple comparisons, although the direction of the effect was seen in every subject. In contrast to the left striatum, there was little difference in BP within the right striatum across the VR and SC conditions, with no areas showing a difference of $t>2.5$ or $t<-2.5$. No significant differences emerged in the ventral striatum between these two conditions. To confirm that the significant results in the left lateral putamen and left medial caudate were not attributable to one or two subjects, we examined the $\mathrm{BP}$ values in small (2 mm radius) spherical regions of interest centered at the peak coordinates. In both cases, all but one subject showed the effect (with the one exception in both cases being accounted for by the subject with the lowest BP in the SC condition for the coordinates examined).

After correction for the number of resolution elements in the basal ganglia, no statistically significant changes in BP emerged between the FR and SC conditions. However, there was a trend toward decreases in $\left[{ }^{11} \mathrm{C}\right]$ raclopride BP bilaterally in the caudate, relative to the SC condition, suggesting that the FR condition induced modest increases in DA transmission compared with the SC condition $(x=19, y=4, z=20, t=3.8 ; x=-6$, $y=14, z=8, t=3.6)$.

Direct contrast of the FR and the VR conditions revealed several areas of the striatum with significantly lower $\left[{ }^{11} \mathrm{C}\right]$ raclopride $\mathrm{BP}$ in the FR condition relative to the VR condition, indicating that the FR condition produced more DA transmission than the VR condition (Fig. 4). Foci localized to both the head of the caudate and the lateral putamen bilaterally. In the left hemisphere, these foci localized to the same regions that showed evidence of decreased DA transmission during the VR condition relative to the SC condition. No areas showed significantly lower BP in the VR condition than in the FR condition. No significant differences emerged in the ventral striatum.

Although the primary search volume was limited to the basal

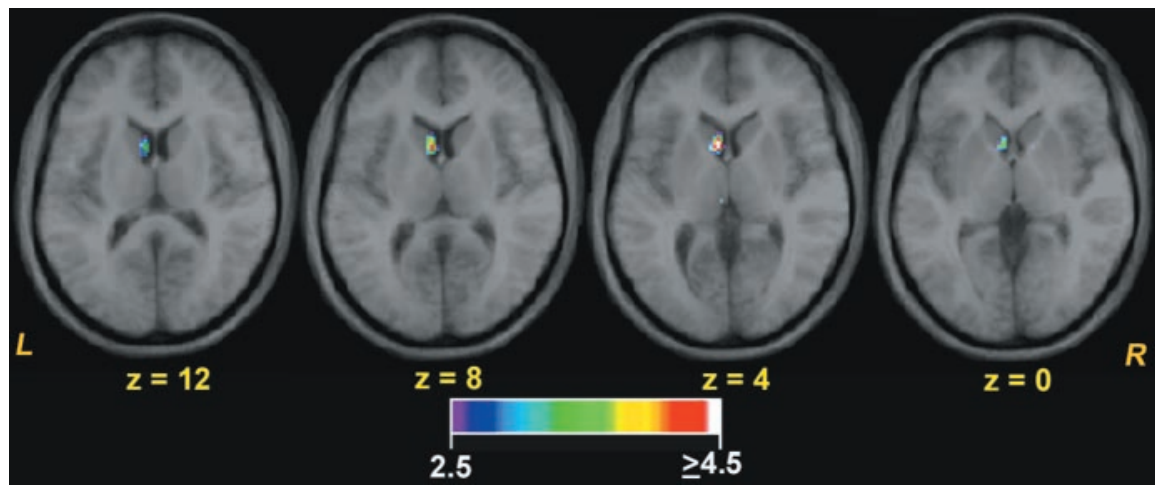

Figure 2. Decreased $\left.{ }^{11} \mathrm{C}\right]$ raclopride BP (indicating increased DA transmission) in the left medial caudate in the contrast between the VR and SC conditions. The $t$ statistic map was thresholded to only show changes of $t>2.5$ (positive $t$ values reflect decreased $\left[{ }^{11} \mathrm{C}\right]$ raclopride BP). In all images, the $t$ statistic maps for BP change are overlayed on axial slices from an average MRI of the nine subjects. L, Left; $R$, right.

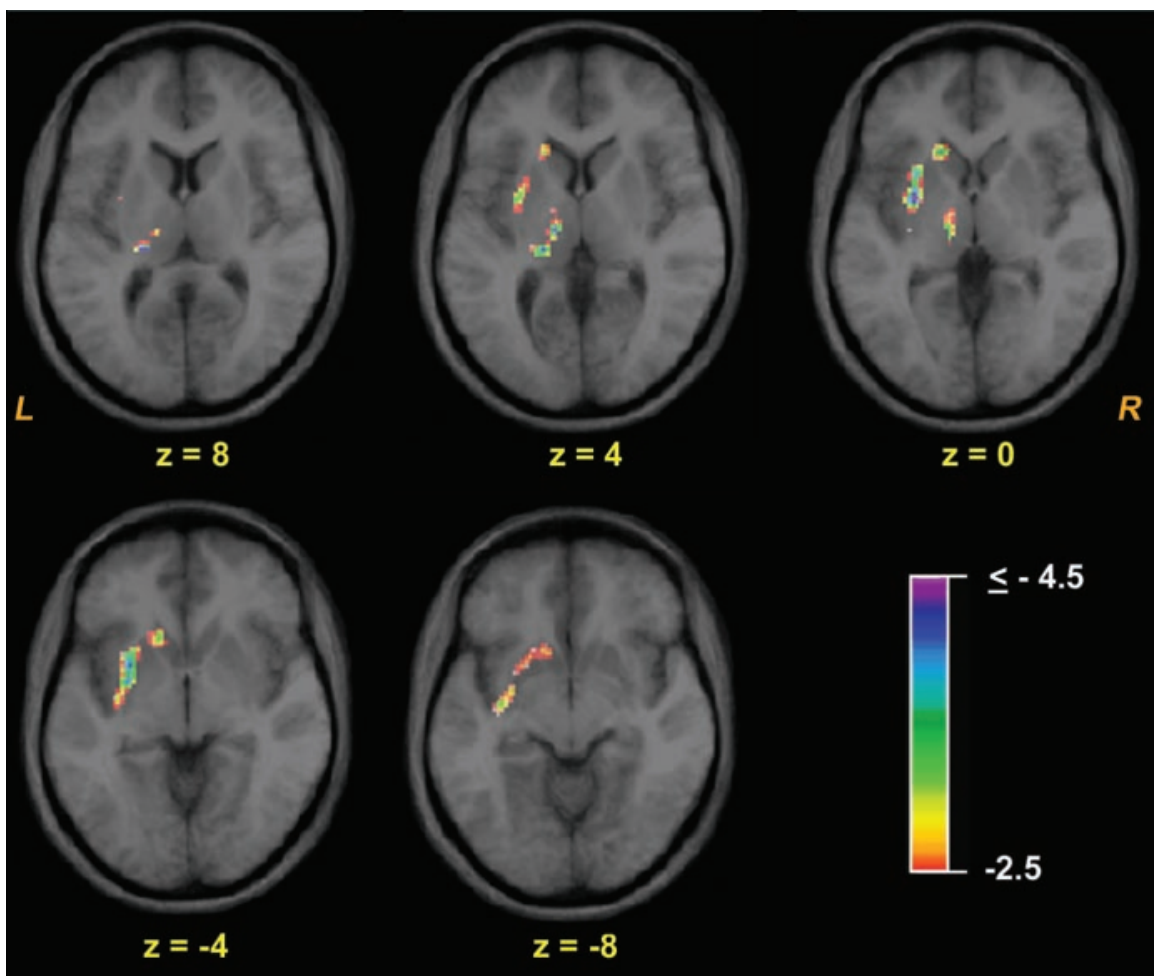

Figure 3. Areas with increased $\left[{ }^{11} \mathrm{C}\right]$ raclopride BP (decreased DA transmission) in the left putamen and the anterior head of the caudate-putamen in the VR condition relative to the SC condition. A contiguous area of decreased DA transmission extends from the caudate-putamen into the ventral striatum but is below corrected levels of statistical significance by the time it reaches the ventral striatum. A response can also be observed in the left thalamus. The $t$ statistic map was thresholded to only show changes of $t<-2.5$ (negative $t$ values reflect increased $\left[{ }^{11} \mathrm{C}\right.$ raclopride BP). Note that the color scale is different from that in Figure 2 , with purple reflecting the greatest magnitude changes. L, Left; $R$, right.

ganglia (area with average $\left[{ }^{11} \mathrm{C}\right]$ raclopride $\mathrm{BP}>1$ ), it may be noted that in Figure 3 (which displays the contrast between the FR and the SC conditions), an area in the left thalamus in the vicinity of the ventrolateral anterior nucleus also showed a significant decrease in DA transmission $(x=-12 ; y=-18 ; z=2 ; t=$ -4.4). This same region again demonstrated altered raclopride $\mathrm{BP}$ in the contrast between the FR condition and the VR condition (Fig. 4), with greater DA transmission occurring in the FR condition than the VR condition $(x=-13 ; y=-16 ; z=2 ; t=$ 4.3). Together, these data suggest that DA transmission in the left thalamus was modulated in a manner similar to that seen for DA 


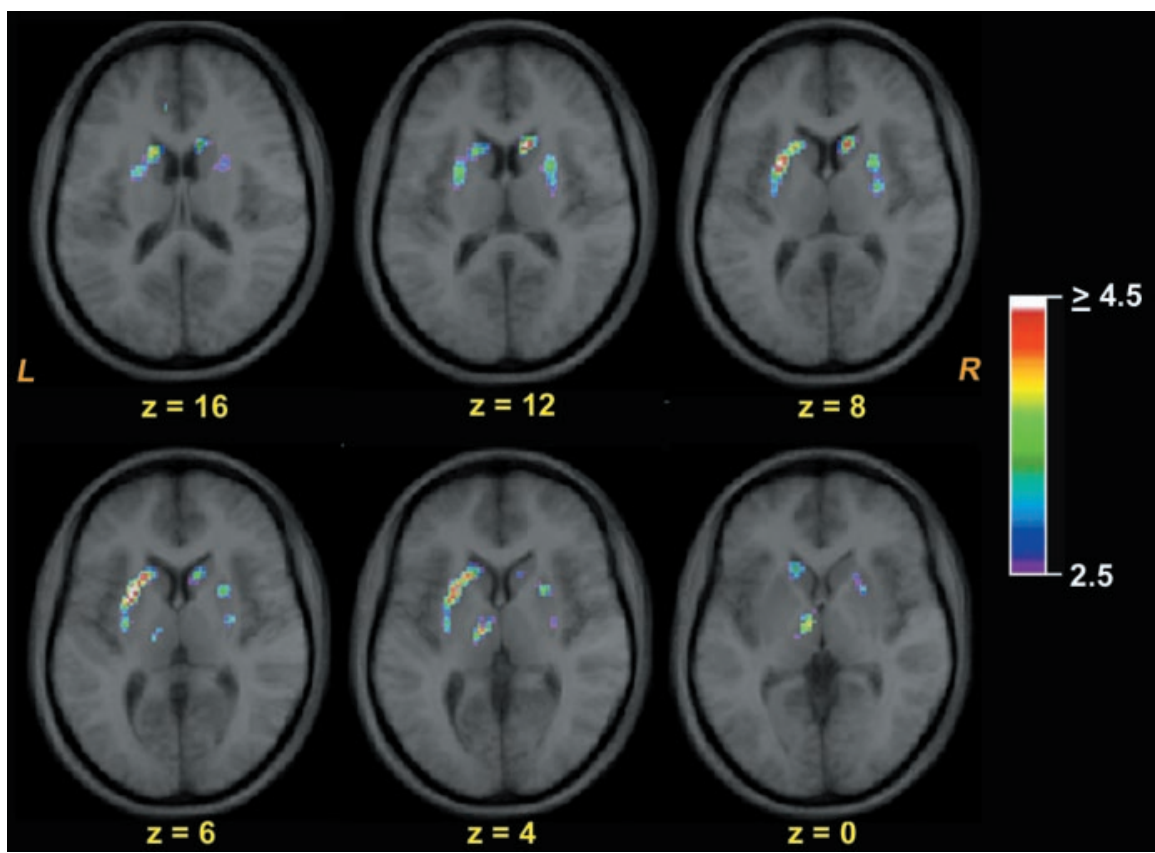

Figure 4. Areas with decreased $\left[{ }^{11} \mathrm{C}\right]$ raclopride BP (increased DA transmission) in the FR condition relative to the VR condition. The largest volume peak encompasses parts of both the left putamen and the neighboring caudate. Significant DA modulation also occurred in the right caudate and the putamen, although it only reached conservative levels of statistical significance in the caudate. Evidence of DA modulation again localized to the left thalamus. The tstatistic map was thresholded to only show changes of $t>2.5$. L, Left; R, right.

transmission in the left lateral putamen. However, this finding must be treated with caution because of the low basal $\left[{ }^{11} \mathrm{C}\right]$ raclopride BP levels in the thalamus.

\section{Discussion}

The present study indicates that performance of monetary reward tasks leads to changes in $\left[{ }^{11} \mathrm{C}\right]$ raclopride $\mathrm{BP}$ in the striatum of healthy humans. Koepp et al. (1998) reported increased DA transmission during a video game task involving monetary reward. However, the lack of a sensorimotor control condition in that study makes it difficult to determine to what extent the motivational, sensorimotor, or skill-learning aspects of the task contributed to the DA release. In contrast, in the present study, subjects performed similar movements and received matched sensory stimulation in all conditions. Thus, the changes in DA transmission can be interpreted with greater specificity.

The emergence of increased DA transmission during a conditioned reinforcement task involving money is consistent with evidence from animal studies indicating increased DA release during tasks involving naturally occurring primary rewards (Hernandez and Hoebel, 1988; Salamone et al., 1994; Wilson et al., 1995). However, the receipt of reward alone is unlikely to explain the specific pattern of DA transmission described here, because the location and magnitude of changes in $\left[{ }^{11} \mathrm{C}\right]$ raclopride BP differed between the FR and VR tasks despite the fact that they involved the same frequency and magnitude of reward. This suggests that specific characteristics of reward contingencies influence patterns of DA transmission in humans.

Based on studies examining the phasic burst firing of DA neurons in animals, researchers have increasingly emphasized the role of DA in response to unpredictable or under-predicted rewards (Schultz, 1998; Schultz and Dickinson, 2000). Consistent with this evidence, the highest magnitude focus occurred in the VR-SC contrast, in which the rewards were not fully predicted. In contrast, the FR-SC comparison only produced trends toward significance. However, this interpretation is complicated by the observation of greater DA transmission in much of the dorsal striatum in the FR condition relative to the VR condition. This effect was most prominent in the lateral striatum and was largely accounted for by the apparent decrease in DA transmission in the VR condition (seen in the contrast of the VR and SC conditions).

Why would the VR condition produce less DA transmission in portions of the striatum than the fully predicted FR condition or the nonrewarding SC condition? First, it must be noted that in the VR condition, nonrewarded trials outnumbered rewarded trials by a 3 to 1 margin. In electrophysiological studies of monkeys, DA neurons show a suppression of firing when an expected reward is withheld (Schultz, 1998). Thus, in the VR condition, the nonreward trials may have led to a net suppression of DA release. If this reasoning is correct, one would predict that these net decreases in DA transmission would be attenuated or abolished in studies with more favorable reward ratios.

In contrast to the VR condition, there was never an expectation of reward on the nonreward trials during the FR condition. Thus, nonreward trials would not be expected to produce any declines in DA transmission in the FR condition. Indeed, in the FR condition each nonreward trial actually represents just another cue predicting an upcoming reward (subjects could even use each nonreward trial to count down when the next reward would occur). Electrophysiological studies indicate that although the receipt of the predictable reward may stop inducing DA release over time, these responses are transferred to the task events that predict the reward (Ljungberg et al., 1992; Schultz et al., 1993). Thus, although the reward itself was predictable, the nonreward trials in the FR condition could serve as task cues capable of inducing at least modest levels of DA transmission.

The strongest area of increased DA transmission during the VR condition relative to the SC condition localized to the medial caudate. This region receives strong projections from the orbitofrontal cortex (Haber, 2003), which plays a prominent role in reward processing (Zald and Kim, 2001). Substantial evidence implicates the caudate in reward-related tasks, including responses linked to the expectation or receipt of reward (Apicella et al., 1991; Kawagoe et al., 1998; Lauwereyns et al., 2002; Takikawa et al., 2002). Moreover, DA functioning in the caudate-putamen appears critical to animals' readiness to work for food reward (Szczypka et al., 2001). Not surprisingly, functional MRI (fMRI) studies of monetary reward in humans frequently show strong responses in the dorsal striatum, and these foci are often centered on or include the medial caudate (Delgado et al., 2000, 2003; Elliott et al., 2000, 2003; Knutson et al., 2001a,b).

In contrast to the dorsal striatum, we did not observe significant responses in the nucleus accumbens-ventral striatum. Most models of reward and motivation emphasize the importance of DA release in the ventral striatum. Indeed, the involvement of the ventral striatum in monetary reward processing (particularly the 
anticipation of monetary rewards) has been confirmed by multiple fMRI studies in humans (Elliott et al., 2000; Breiter et al., 2001; Knutson et al., 2001a,b). Thus, it seems natural to ask why no consistent ventral striatal response emerged in the present study. Methodologically, the smaller size and relatively lower levels of DA in the ventral versus the dorsal striatum (Haber, 2003) may make it more difficult to image changes in DA transmission within this region during behavioral manipulations. However, ventral striatal responses have been observed using the same PET camera and similar methods in two different $\left[{ }^{11} \mathrm{C}\right]$ raclopride studies involving amphetamine challenge (Drevets et al., 1999; Leyton et al., 2002) and one behavioral challenge study involving stress (Pruessner et al., 2004), indicating the feasibility of measuring DA transmission in this region with the present techniques.

The lack of a significant ventral striatal response also appears somewhat inconsistent with a recent study by Pappata et al. (2002), who reported decreased $\left[{ }^{11} \mathrm{C}\right]$ raclopride BP (increased DA transmission) in the ventral striatum when subjects were performing a math task for money relative to a nonreward condition. It is possible that this difference in the location of DA release merely reflects the use of different reward contingencies. For example, the paradigm of Pappata et al. (2002) involved a time constraint leading to psychological stress, which itself may induce DA release in the ventral striatum (Pruessner et al., 2004). Two methodological issues also warrant consideration in evaluating the study by Pappata et al. (2002). First, the single-bolus, single-scan approach used by Pappata et al. (2002) relies on several contentious assumptions and is potentially vulnerable to rCBF effects, movement artifacts, and unequal noise variance and sensitivity to $\mathrm{BP}$ changes between early and late stimulation time periods (Dagher et al., 1998). Second, no peaks in the study by Pappata et al. (2002) actually reached statistical significance after correction for a search over the entire striatal region.

Although the VR condition induced increased DA transmission in the medial caudate, it produced decreased DA transmission in the anteriolateral caudate and the putamen. Given that these foci fall within the motor loop portions of the striatum (Haber, 2003), it may be hypothesized that the motor demands of the task interacted with the reward schedules in determining the pattern of DA transmission (although the motor demands were well matched across tasks). Motor demands may similarly be hypothesized to have influenced the lateralization of the DA response, because subjects only responded with their dominant hand, and eight of the nine subjects were right-handed. Examination of the single left-handed subject did not provide evidence of a differential lateralization, but clearly more subjects would be needed to properly address this hypothesis.

The contrasting effects of the VR condition on DA transmission in the medial caudate versus the anteriolateral caudate and the putamen raise the possibility that certain behavioral conditions may produce inverse effects on DA transmission within different functional zones of the striatum. Intriguingly, the medial caudate (orbitofrontal loop) and the anteriolateral caudateputamen (motor loop) receive projections from different populations of DA neurons (Haber, 2003), providing a possible source for differential DA modulation within distinct corticostriatalthalamocortical loops.

The topographically discrete nature of the observed $\left[{ }^{11} \mathrm{C}\right] \mathrm{ra}-$ clopride responses is consistent with studies of motor pathways, which have reported focal modulation of $\left[{ }^{11} \mathrm{C}\right]$ raclopride $\mathrm{BP}$ within motor regions of the striatum (Strafella et al., 2001; Badgaiyan et al., 2003). It is also consistent with studies using in vivo microdialysis and voltammetry, which often show marked differences in patterns of DA release across striatal regions (Iwano et al., 1997; Wilkinson et al., 1998; Cousins et al., 1999; Bassareo et al., 2002; Cragg et al., 2002). However, this regional specificity appears to run counter to findings from electrophysiological studies of midbrain DA cells, which emphasize the homogeneity of DA firing (Schultz, 1998). Such a homogeneous pattern would be expected to lead to widespread DA release throughout the striatum. Our results suggest that in humans, the DA system is capable of far more focal responses. The source of this discrepancy may arise from the different timescales examined with these techniques. Electrophysiological studies of DAproducing cells focus on transient 200-300 msec bursting activity of DA cells that are time-locked to task features. In contrast, $\left[{ }^{11} \mathrm{C}\right]$ raclopride and in vivo microdialysis reflected an aggregate of time-locked phasic activity, non-time-locked phasic activity, and sustained statewise changes in DA transmission. These different timescales of analysis can lead to dramatically different results. For instance, electrophysiological studies show little if any association between time-locked phasic responses and motor movement (DeLong et al., 1983; Schultz et al., 1983; Schultz and Romo, 1990), whereas microdialysis investigations show strong associations between DA release and the motor demands of the task (McCullough et al., 1993; Salamone et al., 1994; Sokolowski et al., 1998).

Electrophysiological and $\left[{ }^{11} \mathrm{C}\right]$ raclopride studies also differ in terms of the extent to which they are influenced by presynaptic and postsynaptic processes. Although $\left[{ }^{11} \mathrm{C}\right]$ raclopride $\mathrm{BP}$ is significantly influenced by postsynaptic effects (Dumartin et al., 1998; Tsukada et al., 1999, 2000; Laruelle, 2000; Sun et al., 2003), electrophysiological studies only address DA cell firing, without accounting for other factors that determine the magnitude and presence of DA release or its ability to bind postsynaptically (Garris et al., 1999; Yavich and MacDonald, 2000). Some of these modulatory influences are likely to produce regionally specific effects. Moreover, corticostriatal glutamatergic inputs may lead to focal modulation of DA release (Cheramy et al., 1986; Taber and Fibiger, 1995) in a manner consistent with the topographic specificity observed in this and other $\left[{ }^{11} \mathrm{C}\right]$ raclopride PET studies of behavior.

\section{References}

Apicella P, Ljungberg T, Scarnati E, Schultz W (1991) Responses to reward in monkey dorsal and ventral striatum. Exp Brain Res 85:491-500.

Aston JA, Gunn RN, Worsley KJ, Ma Y, Evans AC, Dagher A (2000) A statistical method for the analysis of PET neuroreceptor ligand data. NeuroImage 12:245-256.

Badgaiyan RD, Fischman AJ, Alpert NM (2003) Striatal dopamine release during unrewarded motor task in human volunteers. NeuroReport 14:1421-1424.

Bassareo V, De Luca MA, Di Chiara G (2002) Differential expression of motivational stimulus properties by dopamine in nucleus accumbens shell versus core and prefrontal cortex. J Neurosci 22:4709-4719.

Breier A, Su TP, Saunders R, Carson RE, Kolachana BS, de Bartolomeis A, Weinberger DR, Weisenfeld N, Malhotra AK, Eckelman WC, Pickar D (1997) Schizophrenia is associated with elevated amphetamine-induced synaptic dopamine concentrations: evidence from a novel PET method. Proc Natl Acad Sci USA 94:2569-2574.

Breiter HC, Aharon I, Kahneman D, Dale A, Shizgal P (2001) Functional imaging of neural responses to expectancy and experience of monetary gains and losses. Neuron 30:619-639.

Cheramy A, Romo R, Godeheu G, Baruch P, Glowinski J (1986) In vivo presynaptic control of dopamine release in the cat caudate nucleus. II. Facilitatory or inhibitory influence of L-glutamate. Neuroscience 19:1081-1090. 
Collins DL, Holmes CJ, Peters TM, Evans AC (1995) Automatic 3D modelbased neuroanatomical segmentation. Hum Brain Mapp 3:190-208.

Cousins MS, Wei W, Salamone JD (1994) Pharmacological characterization of performance on a concurrent lever pressing feeding choice procedure: effects of dopamine antagonist, cholinomimetic, sedative and stimulant drugs. Psychopharmacology 116:529-537.

Cousins MS, Trevitt J, Atherton A, Salamone JD (1999) Different behavioral functions of dopamine in the nucleus accumbens and ventrolateral striatum: a microdialysis and behavioral investigation. Neuroscience 91:925934.

Cragg SJ, Hille CJ, Greenfield SA (2002) Functional domains in dorsal striatum of the nonhuman primate are defined by the dynamic behavior of dopamine. J Neurosci 22:5705-5712.

Dagher A, Gunn RN, Lockwood G, Cunningham VJ, Grasby PM, Brooks DJ (1998) Measuring neurotransmitter release with PET: methodological issues. In: Quantitative functional brain imaging with positron emission tomography (Carson RE, Daube-Witherspoon ME, Herscovitch P, eds), pp 449-454. London: Academic.

Delgado MR, Nystrom LE, Fissell C, Noll DC, Fiez JA (2000) Tracking the hemodynamic responses to reward and punishment in the striatum. J Neurophysiol 84:3072-3077.

Delgado MR, Locke HM, Stenger VA, Fiez JA (2003) Dorsal striatum responses to reward and punishment: effects of valence and magnitude manipulation. Cogn Affect Behav Neurosci 3:27-38.

DeLong MR, Crutcher MD, Georgopoulos AP (1983) Relations between movement and single cell discharge in the substantia nigra of the behaving monkey. J Neurosci 3:1599-1606.

Dewey SL, Smith GS, Logan J, Brodie JD, Yu DW, Ferrieri RA, King PT, MacGregor RR, Martin TP, Wolf AP (1992) GABAergic inhibition of endogenous dopamine release measured in vivo with ${ }^{11} \mathrm{C}$-raclopride and PET. J Neurosci 12:3773-3780.

Dewey SL, Smith GS, Logan J, Brodie JD, Fowler JS, Wolf AP (1993) Striatal binding of the PET ligand 11C-raclopride is altered by drugs that modify synaptic dopamine levels. Synapse 13:350-356.

Drevets WC, Price JC, Kupfer DJ, Kinahan PE, Lopresti B, Holt D, Mathis C (1999) PET measures of amphetamine-induced dopamine release in ventral versus dorsal striatum. Neuropsychopharmacology 21:694-709.

Drevets WC, Gautier C, Price JC, Kupfer DJ, Kinahan PE, Grace AA, Price JL, Mathis CA (2001) Amphetamine-induced dopamine release in human ventral striatum correlates with euphoria. Biol Psychiatry 49:81-96.

Dumartin B, Caille I, Gonon F, Bloch B (1998) Internalization of D1 dopamine receptor in striatal neurons in vivo as evidence of activation by dopamine agonists. J Neurosci 18:1650-1661.

Elliott R, Friston KJ, Dolan RJ (2000) Dissociable neural responses in human reward systems. J Neurosci 20:6159-6165.

Elliott R, Newman JL, Longe OA, Deakin JF (2003) Differential response patterns in the striatum and orbitofrontal cortex to financial reward in humans: a parametric functional MRI study. J Neurosci 23:303-307.

Endres CJ, Kolachana BS, Saunders RC, Su T, Weinberger D, Breier A, Eckelman WC, Carson RE (1997) Kinetic modeling of [11C]raclopride: combined PET-microdialysis studies. J Cereb Blood Flow Metab 17:932-942.

Garris PA, Kilpatrick M, Bunin MA, Michael D, Walker QD, Wightman RM (1999) Dissociation of dopamine release in the nucleus accumbens from intracranial self-stimulation. Nature 398:67-69.

Ginovart N, Farde L, Halldin C, Swahn CG (1997) Effect of resperineinduced depletion of synaptic dopamine on ${ }^{11} \mathrm{C}$ raclopride binding to $\mathrm{D}_{2}$-dopamine receptors in the monkey brain. Synapse 25:321-325.

Gunn RN, Lammertsma AA, Hume SP, Cunningham VJ (1997) Parametric imaging of ligand-receptor binding in PET using a simplified reference region model. NeuroImage 6:279-287.

Haber SN (2003) The primate basal ganglia: parallel and integrative networks. J Chem Neuroanat 26:317-330.

Hartvig P, Torstenson R, Tedroff J, Watanabe Y, Fasth KJ, Bjurling P, Langstrom B (1997) Amphetamine effects on dopamine release and synthesis rate studied in the Rhesus monkey brain by positron emission tomography. J Neural Transm 104:329-339.

Hernandez L, Hoebel BG (1988) Food reward and cocaine increase extracellular dopamine in the nucleus accumbens as measured by microdialysis. Life Sci 42:1705-1712.

Ikemoto S, Panksepp J (1999) The role of nucleus accumbens dopamine in motivated behavior: a unifying interpretation with special reference to reward-seeking. Brain Res Brain Res Rev 31:6-41.

Iwano H, Yamamuro Y, Hori K, Yamauchi T, Nomura M (1997) Effects of discrimination learning on the rat striatal dopaminergic activity: a microdialysis study. NeuroReport 8:1095-1098.

Kawagoe R, Takikawa Y, Hikosaka O (1998) Expectation of reward modulates cognitive signals in the basal ganglia. Nat Neurosci 1:411-416.

Knutson B, Adams CM, Fong GW, Hommer D (2001a) Anticipation of increasing monetary reward selectively recruits nucleus accumbens. J Neurosci 21:RC159(1-5).

Knutson B, Fong GW, Adams CM, Varner JL, Hommer D (2001b) Dissociation of reward anticipation and outcome with event-related fMRI. NeuroReport 12:3683-3687.

Koepp MJ, Gunn RN, Lawrence AD, Cunningham VJ, Dagher A, Jones T, Brooks DJ, Bench CJ, Grasby PM (1998) Evidence for striatal dopamine release during a video game. Nature 393:266-268.

Lammertsma AA, Hume SP (1996) Simplified reference tissue model for PET receptor studies. NeuroImage 4:153-158.

Laruelle M (2000) Imaging synaptic neurotransmission with in vivo binding competition techniques: a critical review. J Cereb Blood Flow Metab 20:423-451.

Lauwereyns J, Takikawa Y, Kawagoe R, Kobayashi S, Koizumi M, Coe B, Sakagami M, Hikosaka O (2002) Feature-based anticipation of cues that predict reward in monkey caudate nucleus. Neuron 33:463-473.

Leyton M, Boileau I, Benkelfat C, Diksic M, Baker HF, Dagher A (2002) Extracellular dopamine, drug wanting, and novelty seeking: a PET/ [11C] raclopride study in healthy men. Neuropharmacology 6:1027-1035

Ljungberg T, Apicella P, Schultz W (1992) Responses of monkey dopamine neurons during learning of behavioral reactions. J Neurophysiol 67:145-163.

McCullough LD, Cousins MS, Salamone JD (1993) The role of nucleus accumbens dopamine in responding on a continuous reinforcement operant schedule: a neurochemical and behavioral study. Pharmacol Biochem Behav 46:581-586.

Mirenowicz J, Schultz W (1994) Importance of unpredictability for reward responses in primate dopamine neurons. J Neurophysiol 72:1024-1027.

Pappata S, Dehaene S, Poline JB, Gregoire MC, Jobert A, Delforge J, Frouin V, Bottlaender M, Dolle F, Di Giamberardino L, Syrota A (2002) In vivo detection of striatal dopamine release during reward: a PET study with $\left[{ }^{11} \mathrm{C}\right]$ raclopride and a single dynamic scan approach. NeuroImage 16 : 1015-1027.

Pruessner JC, Champagne F, Meaney MJ, Dagher A (2004) Parental care and the dopamine response to stress in humans. J Neurosci 24:2825-2831.

Salamone JD, Cousins MS, McCullough LD, Carriero DL, Berkowitz RJ (1994) Nucleus-accumbens dopamine release increases during instrumental lever pressing for food but not free food-consumption. Pharmacol Biochem Behav 49:25-31.

Salamone JD, Cousins MS, Snyder BJ (1997) Behavioral functions of nucleus accumbens dopamine: empirical and conceptual problems with the anhedonia hypothesis. Neurosci Biobehav Rev 21:341-359.

Salamone JD, Aberman JE, Sokolowski JD, Cousins MS (1999) Nucleus accumbens dopamine and rate of responding: neurochemical and behavioral studies. Psychobiology 27:236-247.

Schultz W (1998) Predictive reward signal of dopamine neurons. J Neurophysiol 80:1-27.

Schultz W, Dickinson A (2000) Neuronal coding of prediction errors. Ann Rev Neurosci 23:473-500.

Schultz W, Romo R (1990) Dopamine neurons of the monkey midbrain: contingencies of responses to stimuli eliciting immediate behavioral reactions. J Neurophysiol 63:607-624.

Schultz W, Ruffieux A, Aebischer P (1983) The activity of pars compacta neurons of the monkey substantia nigra in relation to motor activation. Exp Brain Res 51:377-387.

Schultz W, Apicella P, Ljungberg T (1993) Responses of monkey dopamine neurons to reward and conditioned stimuli during successive steps of learning a delayed response task. J Neurosci 13:900-913.

Sokolowski JD, Conlan AN, Salamone JD (1998) A microdialysis study of nucleus accumbens core and shell dopamine during operant responding in the rat. Neuroscience 86:1001-1009.

Spinks TJ, Jones T, Bloomfield PM, Bailey DL, Miller M, Hogg D, Jones WF, Vaigneur K, Reed J, Young J, Newport D, Moyers C, Casey ME, Nutt R 
(2000) Physical characteristics of the ECAT EXACT3D positron tomography. Phys Med Biol 45:2601-2618.

Strafella AP, Paus T, Barrett J, Dagher A (2001) Repetitive transcranial magnetic stimulation of the human prefrontal cortex induces dopamine release in the caudate nucleus. J Neurosci 21:RC157(1-4).

Sun W, Ginovart N, Ko F, Seeman P, Kapur S (2003) In vivo evidence for dopamine-mediated internalization of $\mathrm{D}(2)$-receptors after amphetamine: differential findings with $[(3) \mathrm{H}]$ raclopride versus $[(3) \mathrm{H}]$ spiperone. Mol Pharmacol 63:456-462.

Szczypka MS, Kwok K, Brot MD, Marck BT, Matsumoto AM, Donahue BA, Palmiter RD (2001) Dopamine production in the caudate putamen restores feeding in dopamine-deficient mice. Neuron 30:819-828.

Taber MT, Fibiger HC (1995) Electrical stimulation of the prefrontal cortex increases dopamine release in the nucleus accumbens of the rat: modulation by metabotropic glutamate receptors. J Neurosci 15:3896-3904.

Takikawa Y, Kawagoe R, Hikosaka O (2002) Reward-dependent spatial selectivity of anticipatory activity in monkey caudate neurons. J Neurophysiol 87:508-515.

Talairach J, Tournoux P (1988) Co-planar stereotaxic atlas of the human brain. New York: Thieme.

Tsukada H, Nishiyama S, Kakiuchi T, Ohba H, Sato K, Harada N (1999) Is synaptic dopamine concentration the exclusive factor which alters the in vivo binding of $[11 \mathrm{C}]$ raclopride?: PET studies combined with microdialysis in conscious monkeys. Brain Res 841:160-169.

Tsukada H, Harada N, Nishiyama S, Ohba H, Sato K, Fukumoto D, Kakiuchi $\mathrm{T}$ (2000) Ketamine decreased striatal [(11)C] raclopride binding with no alterations in static dopamine concentrations in the striatal extracellular fluid in the monkey brain: multiparametric PET studies combined with microdialysis analysis. Synapse 37:95-103.

Volkow ND, Wang GJ, Fowler JS, Logan J, Gerasimov M, Maynard L, Ding YS, Gatley SJ, Gifford A, Franceschi D (2001) Therapeutic doses of oral methylphenidate significantly increase extracellular dopamine in the human brain. J Neurosci 21:RC121(1-5).

Watson D, Clark L, Tellegen A (1988) Development and validation of brief measures of positive and negative affect: the PANAS scales. J Pers Soc Psychol 54:1063-1070.

Wilkinson LS, Humby T, Killcross AS, Torres EM, Everitt BJ, Robbins TW (1998) Dissociations in dopamine release in medial prefrontal cortex and ventral striatum during the acquisition and extinction of classical aversive condition in the rat. Eur J Neurosci 10:1019-1026.

Wilson C, Nomikos GG, Collu M, Fibiger HC (1995) Dopaminergic correlates of motivated behavior: importance of drive. J Neurosci 15:5169-5178.

Woods RP, Mazziotta JC, Cherry SR (1993) MRI-PET registration with automated algorithm. J Comput Assist Tomogr 17:536-546.

Worsley KJ, Marrett S, Neelin P, Vandal AC, Friston KJ, Evans AC (1996) A unified statistical approach for determining significant signals in images of cerebral activation. Hum Brain Mapp 4:58-73.

Yavich L, MacDonald E (2000) Dopamine release from pharmacologically distinct storage pools in rat striatum following stimulation at frequency of neuronal bursting. Brain Res 870:73-79.

Zald DH, Kim SW (2001) The orbitofrontal cortex. In: The frontal lobes and neuropsychiatric illness (Salloway S, Duffy JD, Malloy PF, eds), pp 33-70. Washington, DC: American Psychiatric. 